\title{
Representações sociais de aborto para ginecologistas e obstetras da Região Metropolitana de Belo Horizonte, Minas Gerais, Brasil
}

\author{
Social representations of abortion for gynecologists \\ and obstetricians in the Metropolitan Region of Belo Horizonte \\ in the State of Minas Gerais, Brazil
}

Thiago Mikael-Silva (https://orcid.org/0000-0001-5626-9955) ${ }^{1}$

Adriano Roberto Afonso do Nascimento (https://orcid.org/0000-0002-7752-0114) ${ }^{1}$

${ }^{1}$ Universidade Federal de

Minas Gerais. Av. Pres.

Antônio Carlos 6627,

Pampulha. 31270-901 Belo

Horizonte MG Brasil.

thiagomikhael@

hotmail.com

\begin{abstract}
The scope of this study was to identify and analyze the social representations of abortion for gynecologists and obstetricians. The methodology used was the Semi-Structured Interview with 20 gynecologists and obstetricians (10 males and 10 females) from 34 to 67 years of age, who worked in hospitals in the Metropolitan Region of Belo Horizonte in the State of Minas Gerais. The results showed that abortion is recurrent in the daily routine of the interviewees, mobilizing the elaboration of social representations that help them to make it a familiar topic. Typologically, the representations identified were polemic social representations. Most participants objectified the abortion as Decision/Right, anchoring it in basic values, such as liberty, which oriented the practice of abortion and support its legalization. In parallel, another group of participants configured abortion as Murder, anchoring it in basic values considered unquestionable, such as life, which implied in the defense of the fetus, and conscientious objection to the practice of abortion.
\end{abstract}

Key words Abortion, Medicine, Gynecologists/ Obstetricians, Social representations
Resumo O objetivo deste estudo foi identificar e analisar as representações sociais de aborto para ginecologistas e obstetras. Para tal, foram realizadas entrevistas semiestruturadas com 20 ginecologistas e obstetras, 10 homens e 10 mulheres de 34 a 67 anos de idade, que atuavam em hospitais da Região Metropolitana de Belo Horizonte, Minas Gerais. Os resultados apontam que o aborto é recorrente no cotidiano dos entrevistados, mobilizando a elaboração de representações sociais que os ajudam a torná-lo um objeto familiar. Tipologicamente, as representações identificadas foram representações sociais polêmicas. A maioria dos participantes objetivava o aborto como Decisão/ Direito, o ancorando em valores básicos, como a liberdade, que orientavam a realização do aborto e o apoio à sua legalização. Paralelamente, outra parcela dos participantes objetivou o aborto enquanto Assassinato, o ancorando em valores básicos considerados inquestionáveis, como a vida, o que implicava na defesa do feto e na objeção de consciência à realização do aborto.

Palavras-chave Aborto, Medicina, Ginecologistas/Obstetras, Representações sociais 


\section{Introdução}

No mundo todo, estima-se que ocorram anualmente 55,7 milhões de abortos, dos quais $45,1 \%$ (25,1 milhões) são considerados inseguros ${ }^{1}$. Aproximadamente $97 \%$ (24,3 milhões) dos abortos inseguros acontecem em países em desenvolvimento, onde as leis sobre essa prática costumam ser mais restritivas ${ }^{1}$.

No Brasil, o Código Penal de 1940 juntamente com a jurisprudência específica permitem apenas o aborto feito por médico quando não há outra forma de salvar a vida da gestante (aborto terapêutico), quando a gravidez decorre de estupro (aborto humanitário) ou em casos de anencefalia fetal (aborto eugenésico).

Apesar da forte restrição legal, a Pesquisa Nacional de Aborto (PNA) indica que, até os 40 anos, mais de uma em cada cinco mulheres alfabetizadas da área urbana (15\%) já praticou ao menos um aborto ${ }^{2}$ - número que se manteve estável na PNA-2016 - em 2014, foram estimados 416.000 abortos induzidos ${ }^{3}$.

Nesse cenário, o aborto inseguro permanece como a quarta causa de mortalidade materna. No Brasil, a razão de mortalidade materna, em 2015 , foi de $62 / 100.000$ nascidos vivos. Ao todo, ocorreram 1.872 óbitos maternos no Brasil em 2015, e, se por um lado, 211 foram causadas pelo aborto inseguro, por outro, 3.888 mulheres quase morreram por essa mesma causa ${ }^{4}$.

Além da elevada taxa de mortalidade, o aborto inseguro representa uma importante causa de morbidade. Ao realizarem o aborto de forma insegura através de métodos caseiros e/ou medicamentos clandestinamente comercializados, como o Misoprostol, muitas mulheres podem sofrer dores, cólicas, febre, sangramentos, hemorragias ou outras complicações que requerem tratamento ${ }^{5-7}$. Durante o período de 1995 até 2007, a curetagem para remoção de restos de aborto e tratamento de suas complicações esteve no topo do ranking - 238.000/ano - de hospitalizações de mulheres em serviços de saúde ${ }^{8}$.

Mesmo para os casos de aborto legal, esses serviços ainda apresentam significativas lacunas. Em termos de estrutura, os serviços de aborto legal contam com baixa cobertura, estando ausentes em 7 estados 9 . Já em termos de qualidade, a literatura tem sistematicamente relatado práticas exercidas por médicos(as) e outros profissionais de saúde, que caracterizam violência institucional, como julgamentos, discriminação, castigos, maus-tratos e manejo inadequado da dor física e psíquica $^{5-7,10,11}$. Em casos de gravidez decorrente de estupro, muitas mulheres enfrentam suspeição ao seu relato ${ }^{12}$.

Dentre os profissionais que lidam com casos de aborto, os(as) médicos(as) ainda são maioria nas equipes de saúde ${ }^{10,13}$. Além disso, embora o Conselho Federal de Medicina (CFM) tenha emitido posicionamento público favoravelmente à legalização do aborto até a $12^{\mathrm{a}}$ semana de gestação, em 2013, apoiando a autonomia das mulheres, historicamente o saber médico - munido de autoridade técnico-científica sobre o corpo feminino - contribuiu para a redução do protagonismo feminino - das parteiras e das mulheres - nos processos relativos à gravidez, mapeando e exercendo poder sobre sua reprodução e sexualidade, sobretudo através da consolidação da Ginecologia e Obstetrícia ${ }^{14,15}$. O saber médico incialmente produzido por esses campos, cooperou com a circulação de discursos, representações e concepções de sexo e gênero que condenavam o aborto e reforçavam a naturalização de papéis de gênero quanto à maternidade ${ }^{14-18}$. Muitas dessas concepções podem estar presentes de alguma forma nas práticas discriminatórias cuja literatura vem apontando na atenção ao abortamento.

Os(as) próprios(as) médicos(as) que realizam o aborto em condições legais também podem sofrer discriminação por parte dos colegas. Seja pelo temor de serem tachados por termos pejorativos, como "aborteiro", por discordâncias pessoais, desconhecimento ou medo, muitos profissionais declaram objeção de consciência ao aborto, se recusando a realizá-lo, $0^{9,12,19}$.

Essas práticas estão fortemente relacionadas às percepções, crenças e representações sociais dos profissionais de saúde sobre o aborto ${ }^{10,20-23}$. Diante disso, indaga-se: Quais representações sociais sobre o aborto são elaboradas e partilhadas por ginecologistas/obstetras?

\section{A Teoria das Representações Sociais: conceitos e abordagem}

A definição do termo representações sociais (RS) e a criação deste campo de estudos se devem a Moscovici que, através de sua obra seminal $A$ psicanálise, sua imagem e seu público (1961), ofereceu um primeiro delineamento formal do conceito e teoria das RS. Desde então, o campo de estudos em RS se encontra em franca expansão, caracterizando-se pela pluralidade metodológica, temática e conceitual ${ }^{24-26}$.

Especialmente a abordagem processual pautada em Moscovici ${ }^{27}$ e Jodelet ${ }^{25}$, escolhida neste estudo, preocupa-se com a forma pela qual as RS 
são produzidas e circulam entre os indivíduos ${ }^{28}$. Nessa perspectiva, as RS podem ser definidas como "[...] uma forma de conhecimento, socialmente elaborada e partilhada, com um objetivo prático, e que contribui para a construção de uma realidade comum a um conjunto social" ${ }^{25}$ (p.22).

Em sua obra seminal, Moscovici elaborou esse conceito a partir das representações coletivas de Durkheim. Apesar da substituição da noção durkheimiana, o conceito não foi totalmente abandonado. Existem três tipos de RS: 1) RS hegemônicas: são uniformes, inquestionáveis e coercitivas, designando entendimentos e significados amplamente partilhados por um grupo rigidamente estruturado - equivalem às representações coletivas de Durkheim ${ }^{24}$; 2) RS emancipadas: expressam a cooperação entre os grupos e são originadas pela troca de diferentes significados sobre o mesmo objeto; e 3) RS polêmicas: são geradas pelos conflitos sociais, expressando relações antagônicas ou de diferenciação entre grupos sociais, além de pontos de vista excludentes sobre um mesmo objeto ${ }^{26}$.

Dois mecanismos distintos atuam na elaboração das RS: a ancoragem e a objetivação ${ }^{29}$. A ancoragem permite a transformação de algo estranho e perturbador num sistema de categorias e imagens comuns, ajustando o estranho em um contexto familiar ${ }^{27}$. Trata-se da incorporação ou assimilação de novos elementos de um objeto num quadro de referência anterior. Ancorar é, ao mesmo tempo, a redução do novo ao velho e a reformulação do velho, tornando-o novo ${ }^{26}$.

Já a objetivação corresponde à transformação de algo abstrato em algo quase concreto, unindo uma ideia não-familiar e abstrata à realidade ${ }^{25,27}$. Nesse processo, as ideias deixam de ser percebidas como derivações da atividade intelectual de certos indivíduos e passam a ser tratadas como produtos de algo que existe exteriormente, havendo uma substituição do percebido pelo conhecido $^{30}$.

No Brasil, embora distintas abordagens de pesquisa em RS coexistam, uma característica marcante é o uso da TRS no enfrentamento de problemas que atingem a sociedade brasileira na atualidade ${ }^{31}$. Além de um problema social, o aborto gera intensas discussões que atravessam o campo acadêmico, a mídia e o cotidiano de trabalho dos profissionais de saúde. Em 2018, por exemplo, esse assunto voltou a circular ativamente na esfera pública brasileira. Nos dias 03 e 06 de agosto, a ministra Rosa Weber do Supremo Tribunal Federal (STF) convocou audiências públicas para embasar sua decisão quanto à Arguição de Descumprimento de Preceito Fundamental (ADPF-442) ajuizada pelo Partido Socialismo e Liberdade (PSOL) em favor da não recepção parcial dos artigos 124 e 126 do Código Penal, os quais criminalizam o aborto ${ }^{32}$.

Especialmente na mídia, o aborto é fonte de grande polarização que ocorre através de grupos intitulados pró-vida - que defendem a heteronomia e a sacralidade da vida ${ }^{21}-$, e grupos pró-escolha, os quais defendem principalmente o direito de escolha e a autonomia feminina sobre seu próprio corpo ${ }^{33}$.

Embora a literatura sobre RS de médicos(as) e outros profissionais de saúde sobre o aborto seja incipiente, alguns estudos vêm indicando a pertinência da perspectiva das RS na temática do aborto ${ }^{22,23,34}$. De qualquer forma, concretamente as crenças, representações e preconceitos podem ser sustentados por uma RS específica ${ }^{27}$. Uma vez formadas, as RS cumprem pelos menos quatro funções: 1) Função de saber: as RS possibilitam aos atores sociais obterem conhecimentos e incorporá-los num quadro assimilável e compreensível, facilitando a comunicação social; 2) Função identitária: possibilita, a identidade grupal, na medida em que, ao compartilhar uma RS, o indivíduo pode tanto diferenciar um grupo de outro, quanto se sentir pertencente a algum grupo; 3) Função de orientação: a RS é “[...] 'preparação para a ação' [...] na medida em que guia o comportamento" "30; e 4) Função justificadora: permite justificar a posteriori as posturas e comportamentos praticados em relação a um objeto ou alguém ${ }^{30,35}$.

\section{Metodologia}

Os participantes da pesquisa foram médicos(as) que atuavam em maternidades, ambulatórios e serviços de aborto legal de cinco hospitais da Região Metropolitana de Belo Horizonte-MG. A estratégia adotada para localização dos participantes baseou-se na técnica de Amostragem em Bola de Neve. Os profissionais foram contatados por meio de ligações e mensagens via WhatsApp. A partir de um informante-chave (da própria rede de contato dos autores), entrevistas foram agendadas em dia, horário e local escolhidos pelos participantes, que ao final, indicavam outro profissional para ser entrevistado, e assim sucessivamente ao longo do primeiro semestre de 2019.

Foram selecionados 20 ginecologistas/obstetras (GO) - referidos por nomes fictícios -, cujo gênero foi igualmente dividido (10 homens e 
10 mulheres) e a faixa etária variou de 34 a 67 anos (Tabela 1). Em relação à formação/grau de escolaridade, 11 participantes possuíam apenas residência em GO, ao passo que três possuíam pós-doutorado, doutorado $(\mathrm{n}=3)$ ou mestrado $(n=3)$. A maioria dos entrevistados atuava em maternidades ou serviços de atenção às vítimas de violência sexual e de medicina fetal, sendo que o tempo no atual emprego foi, em média, de 13,7 anos. Quanto à religião, metade dos participantes se declarou católica.

No momento da pesquisa, apenas dois profissionais (Milton e Monalisa) já não tinham vínculo profissional com algum hospital da Região Metropolitana de Belo Horizonte. O restante dos participantes atuava em algum dos cinco hospitais contemplados neste estudo, desempenhando diversas funções, como preceptoria de residentes em GO, plantão, consultórios particulares, prénatal, sobretudo de alto-risco, e ambulatórios voltados aos casos de aborto legal, dentre outros. Cinco profissionais informaram que não realizariam aborto legal e diante da hipótese de fazê-lo, declarariam objeção de consciência (Tabela 1).

Todos tiveram conhecimento sobre os objetivos da pesquisa e assinaram o Termo de Consentimento Livre e Esclarecido. O projeto foi aprovado pelo Comitê de Ética em Pesquisa da Universidade Federal de Minas Gerais (UFMG).

Como instrumento de coleta de dados, utilizou-se a entrevista semiestruturada, cujo roteiro procurou explorar as experiências dos profissionais, práticas e procedimentos realizados durante a atenção à saúde de mulheres em casos de aborto. Nesse roteiro, não foram ignoradas eventuais diferenças entres os tipos de aborto, porém considerando o postulado basilar da Teoria das representações sociais de que não há RS de tudo ${ }^{30}$, a exposição dessas diferenças foi estrategicamente deixada a cargo do grupo investigado. Essas entrevistas foram gravadas - duração média de $37 \mathrm{~min} 07 \mathrm{~s}$ - e posteriormente transcritas.

Para tratamento e análise dos dados, optouse pela Análise de conteúdo ${ }^{36}$. Num primeiro momento foi realizada transcrição das entrevistas as quais foram organizadas num corpus. Em seguida, empreendeu-se leitura exaustiva do material a fim de identificar unidades de registro e de contexto. Por último, as unidades temáticas encontradas foram enumeradas, classificadas e categorizadas.

Ao todo, foram organizadas cinco categorias: 1) Motivos para interrupção da gravidez: 13 profissionais citaram a "falta de planejamento", de

Tabela 1. Perfil dos(as) entrevistados(as).

\begin{tabular}{|c|c|c|c|c|c|c|}
\hline Médicos(as) & Idade & Formação & Religião & Área/setor de atuação & Tempo $^{2}$ & $\mathrm{OB}^{3}$ \\
\hline Mabel & 55 & Residência/GO & Espírita & Serviço qualificado de AVS ${ }^{1}$ & 12 & $\mathrm{X}$ \\
\hline Magali & 48 & Residência/GO & Católica & Serviço qualificado de AVS & 6 & \\
\hline Magnólia & 41 & Residência/GO & Católica & Plantão em GO & 10 & \\
\hline Margarida & 67 & Residência/GO & Católica & Serviço qualificado de AVS & 12 & $\mathrm{X}$ \\
\hline Magno & 37 & Mestrado & Sem religião & Plantão em GO & 8 & \\
\hline Marisol & 40 & Doutorado & Espírita & Maternidade & 12 & \\
\hline Malcom & 51 & Residência/GO & Católico & Maternidade & 19 & \\
\hline Malvino & 64 & Pós-doutorado & Cristão & Maternidade & 37 & \\
\hline Marcelino & 59 & Doutorado & Católico & Serviço de Medicina Fetal & 23 & \\
\hline Martina & 38 & Residência/GO & Católica & Plantão em GO & 9 & \\
\hline Marcondes & 48 & Doutorado & Espírita & Plantão em GO & 15 & $\mathrm{X}$ \\
\hline Marvin & 44 & Mestrado & Agnóstico & Serviço de Medicina Fetal & 10 & \\
\hline Mathias & 62 & Residência/GO & Agnóstico & Maternidade & 36 & \\
\hline Matilde & 34 & Residência/GO & Católica & Maternidade & 5 & \\
\hline Miguel & 51 & Residência/GO & Agnóstico & Plantão em GO & 4 & $\mathrm{X}$ \\
\hline Milton & 56 & Residência/GO & Católico & Ambulatório de GO & 25 & $\mathrm{X}$ \\
\hline Melina & 50 & Pós-doutorado & Católica & Maternidade & 9 & \\
\hline Monalisa & 62 & Mestrado & Cristã & Maternidade & 7 & \\
\hline Moacir & 47 & Residência/GO & Católico & Maternidade & 10 & \\
\hline Morgana & 47 & Pós-doutorado & "Católico/espírita" & Serviço qualificado de AVS & 5 & \\
\hline
\end{tabular}

${ }^{1}$ AVS: Atenção às vítimas de violência sexual; ${ }^{2}$ Tempo no emprego atual/anos; ${ }^{3} \mathrm{Objeção} \mathrm{de} \mathrm{consciência} \mathrm{à} \mathrm{realização} \mathrm{do} \mathrm{aborto.}$ 
"conhecimento", "inconsequência”, e 11, o "não quer a gravidez" como motivos para a realização do aborto; 2) Construção de entendimentos sobre o aborto: 13 o entendiam como "decisão"/“direito" e seis como "assassinato"; 3 ) Práticas de (des) cuidado: sete relataram situações de violência institucional, nove mencionaram situações de desconfiança e suspeição à narrativa feminina sobre a violência sexual e 10 falaram sobre a sua ou a objeção de consciência dos colegas ao aborto; 4) Discriminação e nomes pejorativos: 17 citaram nomes pejorativos, como "aborteiro", "fazedor de anjo" e "açougueiro", que, embora estivessem presentes em ambiente profissional, eram mais associados à clandestinidade; 5) Opinião e posicionamento sobre a legislação: todos os entrevistados emitiram sua opinião sobre a legislação. Apenas duas médicas (Mabel e Margarida) eram contrárias à legalização do aborto.

Todas essas categorias possibilitaram a organização de um denso material que reunia os conteúdos e falas mais representativas dos entrevistados. Porém, os elementos que indicavam RS presentes nessas mesmas falas estavam espalhados por todas as categorias construídas, exigindo uma costura a fim de se identificar as RS de aborto. A seguir, através de uma perspectiva mais integrada, essa costura será apresentada e discutida. Para essa tarefa, a categoria 2 - Construção de entendimento sobre o aborto - será utilizada como base para organizar as outras. Porém, trata-se de uma escolha, pois outra categoria também poderia ser tomada como ponto de partida para articulação das demais.

\section{Resultados e discussão}

Em geral, dois conjuntos de ideias trazendo teorias de senso comum sobre o aborto foram identificados. Ocorre que do ponto de vista estático, as RS “[...] se mostram semelhantes a teorias que ordenam ao redor de um tema [...] uma série de proposições que possibilita que coisas ou pessoas sejam classificadas, que seus caracteres sejam descritos, seus sentimentos e ações sejam explicados e assim por diante"27(p.207, grifo do autor). No primeiro conjunto, a imagem central do aborto era a do Direito. Mas não se trata de uma definição jurídica, e sim de uma noção com estatuto de fronteira entre eu/outro e o público/ privado. As causas do aborto estavam primordialmente associadas à ausência de "suporte" do Estado, fazendo com que a mulher procurasse “os meios $\mathrm{p}[\mathrm{a}] \mathrm{ra}$ interromper a gravidez por ela mesma” (Monalisa), quando a gravidez não era "planejada" (Moacir); quando "não quer ter filho naquele momento" (Matilde), por "questões financeiras” (Monalisa) e etc. Já no segundo conjunto, a imagem central era a Morte. Mas não se tratava de uma "coisa fisiológica" (Mabel), e sim de um assassinato. As principais causas do aborto decorriam do comportamento sexual negligente da mulher ou adolescente, caracterizado pela "inconsequência" (Mabel) e vivência de "relação momentânea" (Marisol).

Com base nesses dois conjuntos relativamente autônomos, percebeu-se a existência de conhecimentos partilhados que possibilitavam a comunicação de realidades comuns e a elaboração de práticas perante o aborto. Esses conhecimentos sinalizaram o compartilhamento de duas RS do tipo polêmicas que são geradas por conflitos sociais, sendo "[...] determinadas pelas relações antagonistas ou de diferenciação entre grupos sociais e refletem pontos de vista exclusivos sobre um mesmo objeto"26(p.463). Ocorre que a experiência no atendimento às mulheres vítimas de violência sexual pode possibilitar mudanças nos valores e a ressignificação da prática médica, podendo transformar a resistência, o medo e o distanciamento em solidariedade e compromisso ${ }^{37}$.

A seguir, será discutido o processo de elaboração das duas RS polêmicas vinculadas aos conjuntos de ideias anteriormente apresentados. Como afirma Moscovici ${ }^{27}$, do ponto de vista dinâmico as RS “[...] se apresentam como uma 'rede' de ideias, metáforas e imagens, mais ou menos interligadas livremente e, por isso, mais móveis e fluidas que teorias" ${ }^{27}$ (p.338).

\section{Decisão/Direito}

A Figura 1 apresenta uma proposta de sistematização da RS Decisão/Direito e de sua elaboração. Há ainda uma breve descrição de funções que essa RS parece desempenhar para o grupo de profissionais que compartilhava da visão do aborto enquanto decisão/direito. Convém dizer que decisão e direito formam um amálgama que decorre de uma relação simultânea de divisão e complementariedade. Para o grupo tratado, decisão parece ser aquilo que o aborto é quando se encontra na esfera privada e o direito é aquilo que ele se torna quando aparece no âmbito público - principalmente nos serviços de saúde.

Como se pode observar na Figura 1, a RS Decisão/Direito é ancorada em elementos compatíveis com o campo simbólico e semântico de grupos pró-escolha. Essencialmente essa RS emerge 


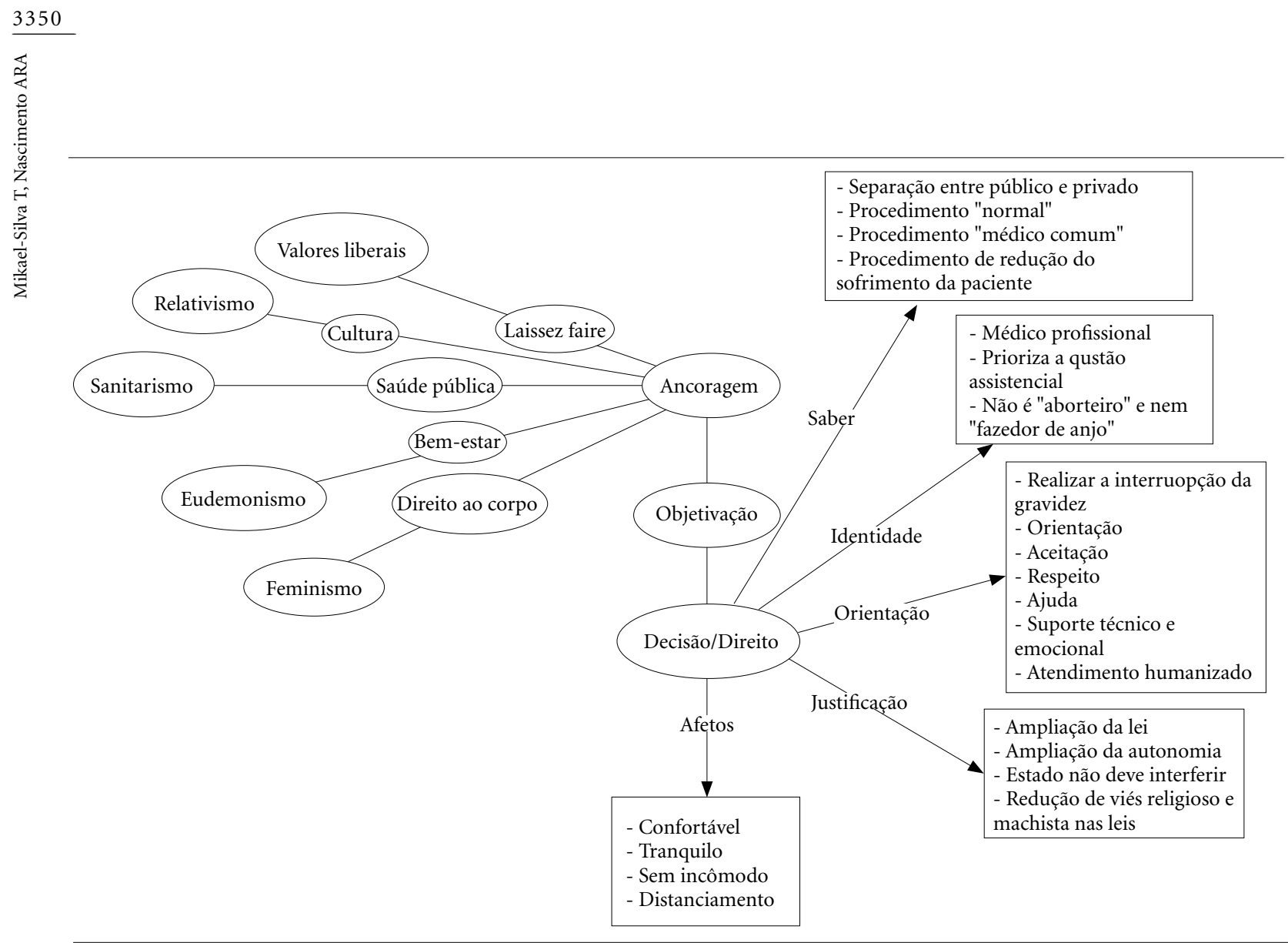

Figura 1. RS de aborto (Decisão/Direito) e funções.

Fonte: Elaborado pelos autores a partir dos dados da pesquisa.

de valores considerados básicos, como a ideologia liberal ${ }^{26,33}$. Na tradição liberal é que se sustenta as noções de liberdade e de autonomia individual no plano de um projeto de modernidade ocidental democrática que se articula com outros princípios, como o secularismo ou laicidade, e eleva a pessoa como sujeito moral e autônomo ${ }^{38,39}$. Para Moacir, o aborto é “... uma decisão da mulher que não compete à gente julgar”. Já Mathias acrescenta: "O corpo é dela, o filho é dela, cabe a ela decidir... religião nenhuma tem que meter o bedelho nisso e nem o Estado”. Trata-se de uma “... questão de foro íntimo” (Marcelino).

Próximo a essas acepções, os entrevistados evocaram um conhecido emblema feminista “direito ao seu corpo" (Marvin e Marcelino). O aborto é uma das principais pautas dos movimentos feministas. No Brasil, o uso dessa expressão remonta à década de 1970, na qual esses movimentos, baseados no princípio do direito individual, usavam como estratégia a substituição da demanda explícita pelo aborto por fórmulas genéricas para contornar eventuais resistências à pauta ${ }^{40}$.
Nas últimas décadas, entretanto, taticamente os defensores da legalização do aborto têm dado mais ênfase a questões mais amplas como a saúde pública $^{41}$. Para Malvino, por exemplo, o aborto consiste num "procedimento de saúde pública", "de redução de risco" e de "morte materna". A médica Monalisa completa que "... a forma de lidar com isso é a forma da saúde e do cuidado", considerando a "saúde, num sentido ampliado". É aqui que entra uma visão eudemônica que prioriza o não sofrimento das mulheres, sua qualidade de vida e bem-estar: “... eu tento ajudá-la ao máximo e, por exemplo, no caso do aborto em situação de violência, se o não sofrimento dela ou a diminuição do sofrimento dela vai ser fazendo o aborto, eu sou a favor de fazer" (Morgana).

Há por fim um relativismo que se faz notar tanto na avaliação das decisões pessoais e profissionais do(a) médico(a) e das mulheres/pacientes, quanto no estatuto do feto: "Isso é uma opção dela, é o que eu falei no início, às vezes uma coisa que é bom pra mim, não é bom procê, uma coisa que é boa procê, não é boa pra mim” (Milton); "Que cidadão?! Não tem cidadão aí ainda ... Esse 
... esse germe de pessoa não é uma pessoa ... Essa pessoa, ela não existe ainda ... a pessoa vai se formando ... quando ela se forma em sociedade, né" (Monalisa). Aqui, a visão de pessoa é positiva, isto é, decorre da esfera da cultura e das leis de uma determinada sociedade. Logo, assim como em outros estudos, a narrativa e foco na mulher e em seu sofrimento prevalecem sobre o feto/embrião $^{39,42}$.

Através do amálgama decisão/direito, o aborto é objetivado, se transforma em algo familiar e (re)arranja a realidade dos(as) ginecologistas/ obstetras: “...infelizmente, é um direito... deveria ser, né, um direito dela, e que infelizmente ela ainda... não tem essa opção” (Magnólia), “... se a gente faz fora da lei, a gente tá praticando um crime. Não que eu concorde que é crime abortar, mas aqui ainda é" (Martina).

Por serem categorias relativamente abstratas, as palavras "decisão" e "direito" se mostram eficazes na tarefa de domesticar o aborto, esvaindo-o de sua dimensão carnal e tornando-o, para o campo biomédico, um "procedimento médico comum" (Malvino) e "uma condição médica como qualquer outra" (Marcelino).

Enquanto uma teoria do senso comum, a RS Decisão/Direito cumpre algumas funções para o grupo que a compartilha. Epistemicamente, ela opera uma cisão entre o público e o privado. $\mathrm{O}$ aborto é visto como decisão que acontece num dos espaços mais íntimos e privados, isto é, na consciência. É na consciência da mulher que opta pelo aborto que se encontram Deus e/ou valores pessoais e religiosos com os quais ela tem que lidar: “... é a consciência dela é que deve pesar, no sentido assim: 'Meu Deus, será que eu tô tomando a decisão certa? Será que é isso que eu devo fazer?'” (Martina). Ainda como saber, considerar o aborto como "procedimento médico normal" pelo qual o profissional estaria "ajudando alguém” (Magali), parece se articular com os modos de sentir dos(as) médicos(as) ao realizá-lo. O aborto é sentindo como um procedimento "tranquilo" (Magali) e "confortável” (Magnólia). Em termos identitários, os padrões médico-jurídicos de segurança e assepsia reforçam a identidade do médico que faz o aborto como um profissional preocupado com a questão assistencial; um médico limpo e higiênico que tem legitimidade legal e profissional para realizar o aborto, diferentemente dos "aborteiros" que o fazem “... só pela questão do dinheiro, o financeiro, não pela aquela questão assistencial" (Marcelino).

Muitos profissionais também informaram que não tinham dificuldade de aceitar as pa- cientes, nem de acolhê-las, orientá-las e prestar cuidados, porque viam o aborto como decisão/ direito. Portanto, essa RS esteve mais associada com as práticas de suporte técnico e emocional oferecido às vítimas e as tentativas de afastar os julgamentos em prol da assistência à saúde. A RS de aborto enquanto Direito/Decisão justificava ainda, as posições favoráveis à ampliação da legislação sobre o aborto e a redução da intervenção do Estado, de vieses e interesses outros que não aqueles oportunos à autonomia das mulheres sobre o próprio corpo.

Para os participantes que compartilhavam da RS acima foi percebido um esforço maior na construção da mulher enquanto "vítima”. Os efeitos práticos dessa construção permeavam a concessão do direito ao aborto humanitário ainda que os(as) profissionais tivessem dúvidas ou desconfiassem da história relatada pela mulher. Isso provavelmente tem a ver com 1) a ancoragem dessa RS num quadro de referência próximo ao grupo pró-escolha; e 2) o tipo de ancoragem no objeto. Entre os movimentos pró-escolha, toda a narrativa oral e visual circunda a mulher, sua experiência e sofrimento ${ }^{42}$. Além disso, a noção de vítima se torna necessária no mundo ocidental para conceder reconhecimento e inteligibilidade ao sofrimento, conferindo legitimidade moral às reivindicações de grupos sociais ${ }^{43}$.

Quanto à ancoragem no objeto, ela está relacionada com o uso da expressão "eu" 44 . $\mathrm{O}$ ato de julgar está ancorado na evidência disponível à pessoa cuja atitude é a de um observador. Muitos profissionais relutavam em fazer inferência sobre o que se passava na mente das mulheres que faziam o aborto ou daquelas que relatavam terem engravidado após serem estupradas. Eles se concentravam nas evidências externas das quais dispunham e o estilo de raciocínio era mais indutivo. Ocorre que "[...] a ancoragem no objeto gera uma distância de nossas próprias hipóteses e do veredicto que nosso julgamento alcança"44(p.776). Isso explica a manutenção de um "distanciamento necessário" (Magno), evitando se "envolver tanto” (Melina) com a história da paciente.

\section{Assassinato}

Outra parte dos entrevistados exibia uma RS de aborto construída a partir de elementos opostos àqueles compartilhados pelo outro grupo. A Figura 2 propõe uma sistematização dessa RS que objetiva o aborto enquanto Assssinato.

Como se pode observar na Figura 2, todos os elementos do quadro de ancoragem são compa- 


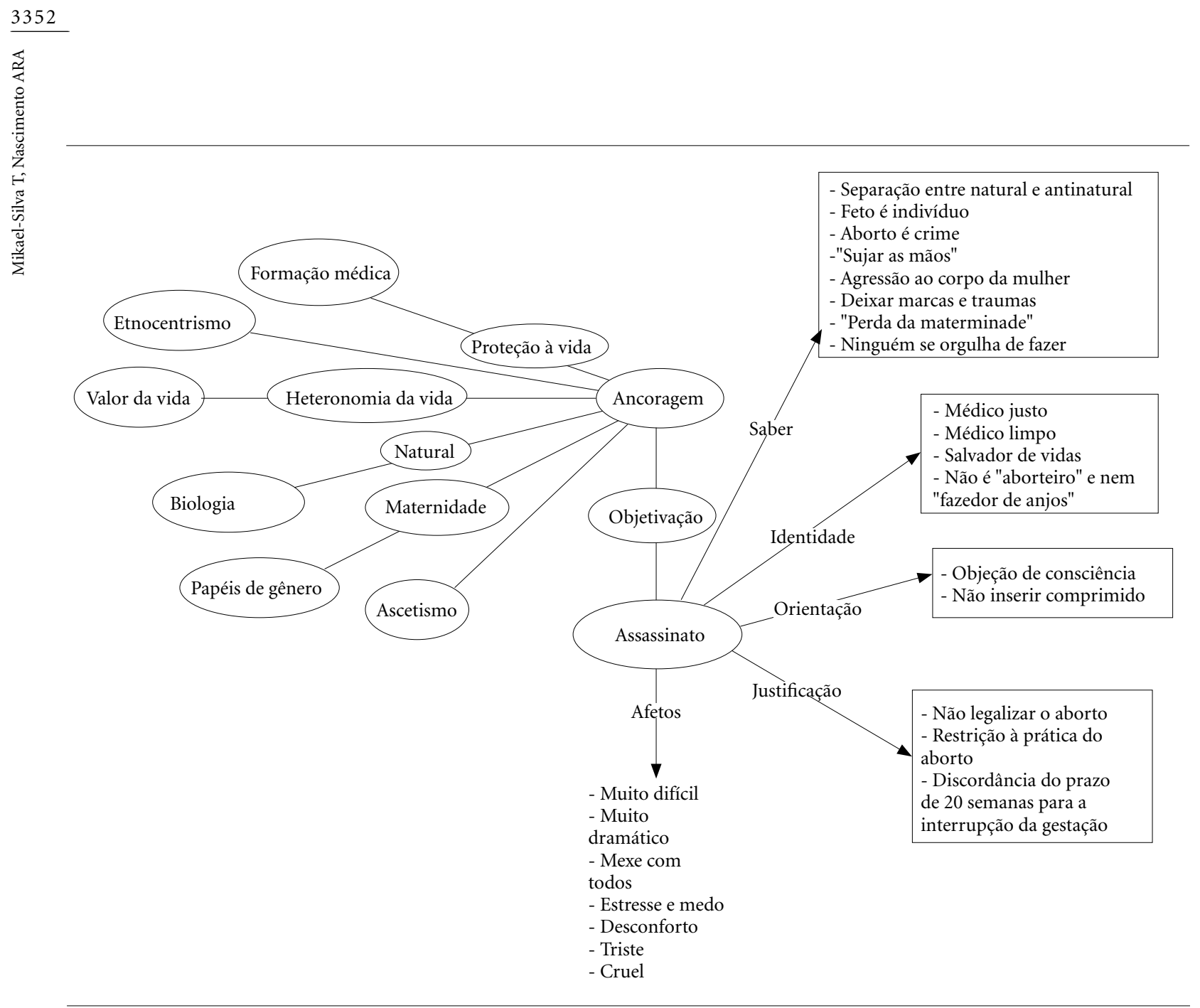

Figura 2. RS de aborto (Assassinato) e funções.

Fonte: Elaborado pelos autores a partir dos dados da pesquisa.

tíveis com a narrativa dos movimentos pró-vida que atuam no debate público sobre o aborto em favor de sua criminalização. Trata-se de uma RS da qual um dos pontos de ancoragem é um valor considerado básico e inquestionável: a vida ${ }^{26,33}$. Aqui há o postulado de que a vida se inicia a partir da fecundação do óvulo pelo espermatozoide, sendo que o feto/embrião é elevado ao estatuto de "indivíduo" (Mabel), isto é, de pessoa e, por conseguinte, detém os direitos subordinados à condição de pessoa humana e jurídica ${ }^{39}$. Isso implica na heteronomia da vida - o feto/embrião é tido como sujeito moral independente enquanto pessoa ${ }^{21}$ : "o neném é um indivíduo, que não pode gritar ... o feto... ninguém consegue... sem um óvulo e ... e um espermatozoide... ele não é uma obra de uma pessoa ... Ele é um indivíduo que tem direitos... eh... direito à vida” (Mabel).
Essa concepção remonta à ideia de personificação do feto e à figura do homúnculo "revelada" pelos microscópios do século XVII e mais tarde resgatada pelo Papa Pio $\mathrm{IX}^{33}$.

É, portanto, na versão moderna da natureza e na ciência da vida - a Biologia - que atributos metafísicos, transcendentes e religiosos buscam refúgio $^{39,42}$. Dentro desse quadro, o aborto ganha uma realidade inteligível como algo "que é meio antinatural" (Milton), "não é uma coisa fisiológica” (Mabel), “... é um ser que realmente não conseguiu... ser gerado” (Marisol).

Por ser ancorada em pressupostos religiosos que se mesclam com a biologia, têm-se aspectos etnocêntricos. A religião na qual a RS Assassinato se ancora faz parte da tradição judaico-cristã ${ }^{45}$ dentro da qual a vida é um "designío de Deus": “[...]o desígnio de Deus, eu não sei falar assim, 
mas às vezes extrapola muito essa visão...eh... organicista, essa visão assim, teórica... orgânica que a gente tem às vezes" (Milton). Como a vida se inscreve nos planos divinos, ela é determinada por uma entidade superior: “[...] é Deus, eu falo assim, ele escreveu pra você que cê vai conviver com esse bebê até ele nascer" (Milton). Isso condena as mulheres a se submeterem e a se conformarem com seu papel já determinado por Deus, pela natureza e pela cultura - a maternidade: “... ela é desde criança, ela é criada pra ter um filho, gerar" (Milton). Essa missão esbarra numa moral judaico-cristã ascética que apresenta uma visão hostil e negativa do corpo, do sexo, do prazer sexual e da própria mulher ${ }^{45}$. $\mathrm{O}$ sexo é circunscrito ao casamento e às relações monogâmicas, tendo como finalidade a procriação ${ }^{38}$. No atual discurso da Igreja Católica, a crítica ao hedonismo é reforçada pelo individualismo consumista contemporâneo que leva à desvalorização da vida e ao descarte do feto/embrião $0^{38,39}$. Essa dimensão apareceu na fala de uma das entrevistadas: “... o pessoal tá muito materialista! Num tão nem pensando que o que tá lá dentro é uma vida, que o que tá lá dentro não pediu pra nascer, né, e vamos tirar" (Margarida).

Outro importante elemento que firma a ancoragem da RS tratada é a chamada "formação da medicina". Outros estudos também levantaram esse aspecto, sendo percebido que, além da concepção de preservação da vida fundamentada na tradição cristã, havia outra apoiada na formação médica ${ }^{23,46}$. Para alguns médicos(as), as pessoas são educadas para preservar a vida, sendo que a própria formação do médico é vista como reforço a esses conceitos ${ }^{23,46}$. Como exemplos: "Não, aí eu... eu não faço porque do ponto de vista religioso, eu não fazi... num... num é da minha formação, né, mas tinha a turma que fazia” (Marcondes), “[...] eu não fui formada pra isso, eu fui formada... pra fazer vida, e não pra tirar vida” (Margarida), “[...] trabalhei muito por causa da... do parto, essas coisas todas da gravidez, então, pra mim, eu acho... que é muito difícil fazer um abortamento" (Milton).

A partir desses elementos, o aborto é objetivado e torna-se familiar enquanto um assassinato: “[...] é uma agressão à... pessoa, ao corpo da mulher, porque tá 'rancando' o neném dali.. pro bebê é um assassinato... pro médico... que formou pra trazer a vida, pra salvar, pra ajudar a evitar danos" (Mabel). O feto, e não a mulher, é que é priorizado na RS compartilhada por esse grupo de entrevistados. Várias outras imagens e metáforas são evocadas, o "drama” (Mabel), “interromper uma vida" (Miguel), "tirar vida", "matar ele" (Milton). Entre os grupos pró-vida há maior tendência ao uso de imagens fetais para ilustrar a individualidade do feto/embrião e de pedaços e restos sanguinolentos de abortos para construí-lo enquanto violência e morte ${ }^{39,42}$.

Em termos de saber, essa RS opera uma cisão entre natural/antinatural, passando a ver o aborto como uma "coisa não fisiológica". Para a lei, é um crime; para o feto, trata-se de um assassinato; para o(a) médico(a), trata-se de um assassinato que o faz "sujar as mãos" (Mabel); para a mulher, é uma agressão que arranca de seu útero o "neném" e acaba com sua maternidade, deixando "marcas" (Milton) e "traumas" (Margarida), “culpa” e "vergonha”. No campo afetivo, essa RS relaciona-se com modos de sentir que enfatizam a dificuldade, a dramaticidade, o estresse, a tristeza, a crueldade e o desconforto que envolve o aborto: "é muito dramático... é uma coisa que mexe muito [...] profundamente com todos os envolvidos" (Mabel), "é triste, né... o abortamento legal gera muito stress, muito medo, né, e um desconforto pra maioria das pessoas, né" (Marisol). Em sua maioria, os(as) médicos(as) que compartilhavam dessa RS não realizavam o aborto, preservando sua identidade enquanto profissionais justos e limpos que salvam vidas. Por conseguinte, parece haver uma relação forte entre essa RS e a objeção de consciência, pois o ato de "ter que colocar o comprimido na vagina da mulher pra poder induzir o aborto" (Mabel) é como se fosse, de um lado, o meio ou a arma que assassina o feto/embrião e, de outro, torna o médico assassino de mãos sujas.

Também nessa RS podem se justificar os posicionamentos contrários à ampliação da legislação sobre o aborto e a discordância do prazo de 20 semanas de gestação para se interrompê-la, que pode tornar o aborto mais "cruel”: "Quanto mais inicial for a interrupção, mais segura ela é, menos cruel desse ponto de vista aí de interromper uma vida" (Miguel).

Entre aqueles que compartilhavam a RS Assassinato, um movimento contrário na hora de perceber a mulher/paciente como vítima era feito. Alguns dos entrevistados que esboçavam desconfiança sobre o relato das mulheres ou reprovavam moralmente seu comportamento sexual mantinham uma visão conflituosa do corpo feminino. Essa visão parece remontar a aspectos da medicina entre os séculos XVI e XVIII que, juntamente com a Igreja Católica, percebia o corpo feminino "[...] como um palco nebuloso e obscuro no qual Deus e Diabo se digladiavam"18(p.66). 
Para o saber médico dessa época, o corpo feminino detinha fisiologia inerentemente patológica, sobretudo, quando a mulher se entregava aos prazeres voluptuosos e renegava a função materna para a qual seu corpo foi moldado; psiquicamente, a mulher se destacava pela sua fragilidade moral e maior predisposição aos desgovernos sexuais e à dissimulação ${ }^{14}$. Possivelmente essas concepções podem dificultar o enquadramento da mulher como vítima, colocando-a sob suspeita. A mulher não seria uma vítima de terceiros, mas de si e de seu comportamento sexual inapropriado e inconsequente. É daí que decorre a simultaneidade do lugar de "agressora, vítima e paciente" (Mabel) na interação médico(a)/paciente segundo a visão de alguns entrevistados.

Aqui, o movimento de ancoragem é feito em direção ao sujeito, ou seja, no "mim"44. O ato de julgar e de representar está apoiado na hipótese que a pessoa tem, buscando-se identificar condições que a confirme, o que implica na atitude de ator e em maior uso de raciocínios dedutivos. Essas condições devem ser relevantes para os próprios sujeitos, isto é, “[...] a pessoa se sente envolvida no ato de julgar e em seu resultado"44(p.776). Alguns entrevistados mimetizavam as pacientes, falando como se fossem as mulheres (mesmo quando eram homens) e interpretavam o sofrimento das pacientes como "marcas" que reforçavam suas hipóteses, bem como a de que as mulheres sentiam culpa e vergonha porque eram "...desde criança...criada[s] pra ter um filho, gerar" (Milton) e caso isso não ocorra em função de um aborto, a mulher pode sofrer desordens misteriosas como a "infertilidade de causa inaparente", cuja solução escapa à terapêutica médica e pode acontecer "logo depois que ela adota uma criança" (Milton).

Apesar de opostas, as RS anteriormente discutidas comportavam elementos que podiam ser compartilhados por ambos os grupos. Isso esbarra na hipótese da polifasia cognitiva segundo a qual " [...] as pessoas são capazes de fato de usar diferentes modos de pensamento e diferentes representações, de acordo com o grupo específico ao qual pertencem, ao contexto em que estão no momento, etc." ${ }^{27}$ (p.322). Algumas práticas, entretanto, estiveram, como vimos, mais associadas com uma ou outra RS. É o caso da objeção de consciência - mais acionada por aqueles que compartilhavam da RS Assassinato.

A objeção de consciência é um princípio garantido pelo inciso VII do Capítulo I do Código de Ética Médica: "o médico exercerá sua profissão com autonomia, não sendo obrigado a prestar serviços que contrariem os ditames de sua consciência ou a quem não deseje" ${ }^{37}$ (p.3). Porém, tanto a Norma Técnica de Atenção Humanizada ao Abortamento, quanto o referido Código reconhecem exceções referentes às circunstâncias nas quais não há outro médico que possa realizar o procedimento objetado, em situações de urgência ou emergência, ou quando a sua abdicação pode gerar danos à saúde do(a) paciente ${ }^{47,48}$. Mais especificamente, a International Federation of $G y$ necology and Obstetrics (FIGO) ressalta que "em situações de emergência, para preservar a vida ou a saúde física ou mental, os profissionais devem prestar os cuidados médicos indicados, à escolha de seus pacientes, independentemente das objeções pessoais dos profissionais" 49 (p.30).

Nesta pesquisa, os profissionais entrevistados exibiram conhecimento sobre esses aspectos: "É um direito que o médico tem se a paciente não tá correndo risco de vida, né, se ela tivesse com sangramento, ele teria que dar assistência ali” (Melina). Como ponderou Magno "[...] o direito à vida [...] é superior ao direito à [...] objeção de consciência", de modo que "[...] a paciente não pode ficar sem atendimento" (Morgana). Mesmo entre aqueles profissionais que admitiram não realizar o aborto, foi informado que na instituição na qual trabalhavam haveria outro profissional que se encarregaria do procedimento.

Contudo, essa não parece ser a realidade no país, onde estudos vêm indicando que juntamente com problemas na estruturação de serviços, a objeção de consciência configura uma barreira no acesso ao aborto ${ }^{9,50}$. Não raro, essa prerrogativa é instrumentalizada de modo a impedir a estruturação de uma rede de assistência às mulheres em casos de violência sexual ${ }^{51}$. Nesse caso, a objeção de consciência acaba cumprindo o propósito de encobrir desconhecimentos sobre a legislação, julgamentos sobre o relato da vítima ou receio de sofrer discriminação pelos colegas ${ }^{9,12,19,50,51}$. Mesmo em países nos quais o aborto é legalizado, a objeção pode ser um fator limitante no acesso ao aborto. No Uruguai, por exemplo, as estimativas sobre a frequência da objeção de consciência variam de $30 \%$ em todo o país, a $50 \%$ em áreas interioranas e até $100 \%$ no departamento de Salto (400 km de Montevidéu) ${ }^{52}$.

Isso mostra que a legalização do aborto cuja longa e acalorada discussão no Brasil ganha novo fôlego com as audiências do STF quanto à ADPF-442 -, embora necessária, não é suficiente para assegurar os direitos sexuais e reprodutivos das mulheres. É crucial que haja serviços e provedores dispostos a realizar a interrupção da 
gestação $^{53}$. Logo, se torna imprescindível conhecer como os profissionais de saúde se apropriam dessa discussão. À uma parcela desse complexo desafio, este artigo buscou contribuir trazendo à tona as RS de aborto compartilhadas pelos ginecologistas e obstetras, as quais orientam várias práticas que podem impactar negativamente na ampliação do acesso ao aborto legal e da assistência qualificada às complicações advindas da prática exercida insegura e clandestinamente.

\section{Considerações finais}

O aborto figura no cotidiano dos(as) ginecologistas/obstetras como um objeto cercado por controvérsias. Em seu espaço de trabalho, ginecologistas e obstetras elaboram e partilham representações sociais que os auxiliam na tarefa de tornar o aborto um objeto inteligível ancorado em diversas racionalidades que compõe quadros de referência compatíveis com concepções e valores defendidos por grupos que polarizam o debate em várias instâncias da esfera pública. Essas representações parecem cumprir diferentes fun- ções, orientando modos de pensar, sentir e agir dos profissionais.

Espera-se que este estudo possa oferecer subsídios para a elaboração de intervenções psicossociais voltadas para a atenção ao abortamento, ampliando estratégias e negociações entre os(as) médicos(as) e as pacientes para que as concepções dos(as) e valores particulares desses profissionais não configurem mais um entre tantos outros obstáculos que as mulheres brasileiras enfrentam na jornada pelo direito ao aborto e afirmação de sua autonomia.

Vale ressaltar que os resultados deste estudo não decorrem de acompanhamento ou observações empreendidas no cotidiano dos(as) médi$\cos ($ as) e das equipes de saúde. Essa poderia ser uma estratégia melhor para compreender as práticas desses profissionais. Além disso, a maioria dos profissionais entrevistados atuava em serviços de aborto legal na capital. Como as RS estão intrinsecamente vinculadas aos grupos e contextos nos quais são geradas e partilhadas, outros profissionais - enfermeiros(as), psicólogos(as) e assistentes sociais - que atuam em outros serviços, sobretudo, em regiões interioranas, podem apresentar outras RS sobre aborto.

\section{Colaboradores}

T Mikael-Silva realizou a pesquisa, bem como as entrevistas com os sujeitos investigados e a transcrição de todo o texto (UFMG). ARA Nascimento orientou a pesquisa durante o curso de mestrado na qual ela foi conduzida, acompanhando todo o processo e cuidando da revisão de toda a redação e elaboração do texto final e análise dos dados apresentados neste artigo. 


\section{Referências}

1. Ganatra B, Tunçalp Ö, Johnston HB, Johnson-JrBR, Gülmezoglu AM, Temmerman M. Global, regional, and subregional classifcation of abortions by safety, 2010-14: estimates from a Bayesian hierarchical model. Lancet 2017; 390:2371-2381.

2. Diniz D, Medeiros M. Aborto no Brasil: uma pesquisa domiciliar com técnica de urna. Cien Saude Colet 2010; 15(1):959-956.

3. Diniz D, Medeiros M, Madeiro A. Pesquisa Nacional de Aborto 2016. Cien Saude Colet 2017; 22(2):653660.

4. Marinho F. Morte materna e aborto no Brasil. Brasília: MS; 2018.

5. Carvalho SM, Paes GO. As experiências de mulheres jovens no processo do aborto clandestino - uma abordagem sociológica. Saude Soc 2014; 23(2):548-557.

6. Carneiro MF, Iriart JAB, Menezes GMS. "Largada sozinha, mas tudo bem": paradoxos da experiência de mulheres na hospitalização por abortamento provocado em Salvador, Bahia, Brasil. Interface (Botucatu) 2013; 17(45):405-418.

7. Madeiro AP, Rufino AC. Maus-tratos e discriminação na assistência ao aborto provocado: a percepção das mulheres em Teresina, Piauí, Brasil. Cien Saude Colet 2016; 22(8):2771-2780.

8. Yu PC. Registro nacional de operações não cardíacas: aspectos, clínicos, cirúrgicos, epidemiológicos e econômicos [tese]. São Paulo: Universidade de São Paulo; 2010.

9. Madeiro AP, Diniz D. Serviços de aborto legal no Brasil - um estudo nacional. Cien Saude Colet 2016; 21(2):563-572.

10. Benute GRG, Nonnenmacher D, Nomura RMY, Lucia MCS, Zugaib M. Influência da percepção dos profissionais quanto ao aborto provocado na atenção à saúde da mulher. Rev Bras Ginecol Obstet 2012; 34(2):6973.

11. Silva PFC, Cordeiro CS, Silva, TMA. Violência institucional contra a mulher em situação de abortamento e a assistência de enfermagem. Rev Saude Foco 2016; $1(1): 1-6$

12. Madeiro AP, Rufino A, Santos P, Bandeira G, Freitas I. Objeção de Consciência e Aborto Legal: Atitudes de Estudantes de Medicina. Rev Bras Educ Med 2015; 40(1);86-92.

13. Farias RS, Cavalcante LF. Atuação diante das situações de aborto legal na perspectiva dos profissionais de saúde do Hospital Municipal Fernando Magalhães. Cien Saude Colet 2012; 17(7):1755-1763.

14. Rohden F. Uma ciência da diferença: sexo e gênero na medicina da mulher. $2^{\mathrm{a}}$ ed. Rio de Janeiro: Editora Fiocruz; 2001.

15. Martins APV. Visões do feminino: a medicina da mulher nos séculos XIX e XX. Rio de Janeiro: Editora Fiocruz; 2004.

16. Brasil. Conselho Federal de Medicina (CFM). Circular CFM No 46/202013 [Internet]. Brasília: CFM; 2013 [acessado 2019 maio 15]. Disponível em: https://waldircardoso.files.wordpress.com/2013/03/ofc3adciocircular-cfm-46-2013.pdf.
17. Aguiar JM, d'Oliveira AFPL, Schraiber, LB. Violência institucional, autoridade médica e poder nas maternidades sob a ótica dos profissionais de saúde. Cad Saude Publica 2013; 29(11):2287-2296.

18. Priore MD. Magia e medicina na colônia: o corpo feminino. In: Priore MD. História das mulheres no Brasil. $7^{\text {a }}$ ed. São Paulo: Contexto; 2004. p. 66-97.

19. Diniz D, Madeiro A, Rosas C. Conscientious objection, barriers, and abortion in the case of rape: a study among physicians in Brazil. Reprod Health Matters 2014; 22(43):141-148.

20. Lima CA, Deslandes SF. Violência sexual contra mulheres no Brasil: conquistas e desafios do setor saúde na década de 2000. Saude Soc 2014; 23(3):787-800.

21. Wiese IRB, Saldanha AAW. Aborto induzido na interface da saúde e do direito. Saude Soc 2014; 23(2):536547.

22. Zordo S. Representações e experiências sobre aborto legal e ilegal dos ginecologistas-obstetras trabalhando em dois hospitais maternidade de Salvador da Bahia. Cien Saude Colet 2012; 17(7):1745-1754.

23. Mortari CLH, Martini JG, Myriam AV. Representações de enfermeiras sobre o cuidado com mulheres em situação de aborto inseguro. Rev Esc Enferm 2012; 46(4):914-921.

24. Sá CP. A construção do objeto de pesquisa em representações sociais. Rio de Janeiro: EdUERJ; 1998.

25. Jodelet D. As representações sociais: um domínio em expansão. In: Jodelet D. As representações sociais. Rio de Janeiro: EDUERJ; 1989. p. 17-44.

26. Vala J. Representações Sociais e psicologia social do conhecimento cotidiano. In: Vala J, Monteiro MB, organizadores. Psicologia Social. 6a ed. Lisboa: Fundação Calouste Gulbenkian; 2004. p. 457-502.

27. Moscovici S. Representação social: investigação em Psicologia Social. Petropólis: Vozes; 2003.

28. Banchs MA. Aproximaciones Procesualies y Estructurales al estúdio de las Representaciones Sociales. $\mathrm{Pa}$ person Social Representations 2000; 9:1-15.

29. Spink MJ. O estudo empírico das Representações Sociais. In: Spink MJ. O conhecimento no cotidiano: as representações sociais na perspectiva da psicologia social. São Paulo: Brasiliense; 1995. p. 85-108.

30. Moscovici S. A Representação Social da Psicanálise. Rio de Janeiro: Zahar Editores; 1978.

31. Jodelet D. Ponto de Vista: Sobre o movimento das representações sociais na comunidade científica brasileira. Temas Psicol 2011; 19(1):19-26.

32. Weber R. Argüição de descumprimento de preceito fundamental 442. Dispõe sobre Arts. 124 e 126 do código penal. Interpretação conformidade com a normativa constitucional; e interrupção voluntária da gestação. Brasília; 2018.

33. Sagan C. Bilhões e bilhões na virada do milênio. São Paulo: Companhia das Letras; 1998.

34. Pérez BAG, Gomes NP, Santos MFS, Diniz NMF. Aborto provocado: representações sociais de mulheres. Rev Enferm UERJ 2013; 21(esp. 2):736-742. 
35. Abric JC. Prácticas sociales y representaciones. Ambassade de France - CCC IFAL; 2001.

36. Bardin L. Análise de conteúdo. São Paulo: Edições 70; 2011.

37. Soares GS. Profissionais de saúde frente ao aborto legal no Brasil: desafios, conflitos e significados. Cad Saude Publica 2003; 19(Supl. 2):399-406.

38. Biroli F. Autonomia e justiça no debate sobre aborto: implicações teóricas e políticas. Rev Bras Cien Polit 2014; 15:37-68.

39. Luna N. Aborto e células-tronco embrionárias na campanha da fraternidade; ciência e ética no ensino da Igreja. Rev Bras Cien Soc 2010; 25(74):91-192.

40. Scavone L. Políticas feministas do aborto. Rev Estud Fem 2008; 16(2):675-680.

41. Miguel LF, Biroli F, Mariano R. O direito ao aborto no debate legislativo brasileiro: a ofensiva conservadora na Câmara dos Deputados. Opin Publica 2017; 23(1):230-260.

42. Luna $\mathrm{N}$. O direito à vida no contexto do aborto e da pesquisa com células-tronco embrionárias: disputas de agentes e valores religiosos em um Estado laico. Religi Soc 2013; 33(1):71-97.

43. Sarti C. A vítima como figura contemporânea. Cad CRH 2011; 24(61):51-61.

44. Moscovici S. The new magical thinking. Public Understanding Sci 1992; 23(7):759-779.

45. Senem CJ, Caramascchi S. Concepção de sexo e sexualidade no ocidente: origem, história e atualidade. Barbarói Santa Cruz do Sul 2017; 49:166-189.

46. Osis MJD, Faúndes A, Duarte GA, Makuch MY. O papel da religiosidade na perspectiva e conduta de ginecologistas brasileiros em relação ao aborto induzido. Bagoas 2013; 9:87-107.

47. Brasil. Conselho Federal de Medicina (CFM). Código de Ética Médica. São Paulo: Conselho Regional de Medicina do Estado de São Paulo; 2017.

48. Brasil. Ministério da Saúde (MS). Atenção Humanizada ao Abortamento: Norma Técnica. 2a ed. Brasília: MS; 2011.

49. International Federation of Gynecology and Obstetrics. Ethical guidelines on conscientious objection. In: Ethical Issues in Obstetrics and Gynecology [Internet]. [acessado 2019 maio 15]. Disponível em: https:// www.figo.org/sites/default/files/uploads/wg-publications/ethics/English\%20Ethical\%20Issues\%20in\%20 Obstetrics\%20and\%20Gynecology.pdf.

50. Fonseca SC, Domingues RMSM, Leal MC, Aquino EML, Menezes GMS. Aborto legal no Brasil: revisão sistemática da produção científica, 2008-2018. Cad Saude Publica 2020; 36(Sup. 1):1-27.

51. Branco JGO, Brilhante AVM, Vieira LJES, Manso AG. Objeção de consciência ou instrumentalização ideológica? Uma análise dos discursos de gestores e demais profissionais acerca do abortamento legal. Cad Saude Publica 2020; 36(Sup. 1):1-11.

52. Coppola F, Briozzo L, Nozar F, Fiol V, Greif D. Conscientious objection as a barrier for implementing voluntary termination of pregnancy in Uruguay: Gynecologists' attitudes and behavior. Int J Gynecol Obstetrics 2016; 134:16-19.
53. Faúndes A. A importância de discutir abertamente o problema do aborto para a proteção e promoção da saúde da mulher. Cad Saude Publica 2020; 36(Supl. $1): 1-3$.

Artigo apresentado em 27/05/2020

Aprovado em 13/06/2020

Versão final apresentada em 15/06/2020

Editores-chefes: Romeu Gomes, Antônio Augusto Moura da Silva 
